This is an electronic version of an article published in Child and Family Social Work (2005), 10, 2,149-157. Child and Family Social Work is available online at http://www.blackwell-synergy.com/loi/cfs

Article title:

COUNTING FAMILY SUPPORT

Author name: $\quad$ Clare Tilbury

Author affiliation: School of Human Services

Griffith University, Queensland, Australia

Email: $\quad$ c.tilbury@griffith.edu.au

Telephone: $\quad+61733821406$

Address: $\quad$ School of Human Services

Griffith University, Logan campus

University Drive

MEADOWBROOK Q 4131 AUSTRALIA

Word length: $\quad$ Abstract 197 words

Body text 5202 words 


\title{
COUNTING FAMILY SUPPORT
}

\begin{abstract}
Preventative family support approaches are positioned as central to child welfare policy reforms aiming to address the problems of relying upon investigation and out-of-home care as the main modes of intervention. Extensive claims are made for family support but relatively little is known about its scope, processes and impact. This study examines the provision of family support in one jurisdiction. A census-type survey of family support services in one Australian state was conducted using a performance measurement framework in which inputs, outputs, processes and outcomes were measured. Family support services constituted a minor part of child welfare expenditure. They provided a narrow range of service types, and most families received short duration, low intensity services. Workers had difficulty identifying the specific child and family needs that were met by services. For family support to be a genuinely alternative response to concerns about the care of children, it must be capable of making an observable difference in the lives of families experiencing serious difficulties. The collection of aggregate performance data on family support would assist in understanding the nature and outcomes of service provision, as well as ensure family support is 'counted' in measurement-oriented policy and budget processes.
\end{abstract}

\section{Keywords: $\quad$ family support, performance measurement}




\section{COUNTING FAMILY SUPPORT}

\section{Introduction}

The entrenched nature and scale of problems in child welfare - the capacity of services to cope with demand, the quality of practice, and poor outcomes for children and young people - have repositioned family support services from the margins to a central role in the reform of child welfare systems. The argument put forward is that the concentration of resources on investigation and out-of-home care as the primary modes of intervention has not served maltreated children well and has undermined the development of a more comprehensive approach to meeting the needs of families who are experiencing serious difficulty in caring for their children (Little, 1995; Faver et al, 1999). Alternatively, a dual focus on both protection and prevention moves policy and practice towards a more integrated approach that acknowledges the interplay of personal, family and social factors on the causes of child abuse and neglect (Maluccio et al, 1994; McGowan \& Walsh, 2000). This argument echoes an historical tension about what child welfare should comprise, characterised in the literature as the 'child rescue' versus 'family support' paradigms (Whittaker, 1991).

The policy prominence of family support since the 1980s has been a significant and enduring trans-national trend, following relatively similar paths in most liberal democratic welfare regimes. For example, there is evidence of family support approaches in moves to differential response systems and community partnership approaches in the USA (Waldfogel, 1998; Daro, 2003); the requirement to both promote and safeguard the welfare of 'children in need’ in the UK Children Act 1989 (Aldgate \& Hill, 1995); and 
restructuring intake and assessment procedures in Australia (Tomison, 1999). All such strategies rely upon the existence of an array of services that will help families attend to the care and protection needs of their children, when statutory intervention is not appropriate or necessary. However, such developments have yet to gain a strong foothold. Even when commitment to family support is ostensibly high in policy terms, narrow approaches to child welfare have tended to prevail in practice. Several earlier studies highlighted the gap between needs and access to effective family support services (Aldgate et al, 1992; Audit Commission, 1994; Wilding \& Thoburn, 1997). While this situation may be improving (Statham \& Holtermann, 2004) it seems that the place of family support will have to be constantly justified against the competing claims of other approaches, particularly in socio-political environments where child protection is narrowly conceptualised as risk management (Parton et al, 1997; Tunstill, 1995).

Much of the research support for family support emanates from the deficiencies found in investigation and surveillance approaches to child welfare. It is proposed that attention to preventative approaches will ensure children are not unnecessarily placed in care (thus decreasing caseloads); redirect resources being consumed by investigations towards ongoing services for families; employ a partnership approach with parents; be voluntary rather than adversarial or compulsory; and reduce reliance on diminishing out-of-home care resources (Frost, 1997; Tomison, 1999). Family support services themselves have not been studied to the same extent as more traditional services within the child welfare system. They have been counter-positioned against residual and coercive statutory 
services and largely taken to be good. If family support is to live up to its promise of improved responsiveness to child and family needs, it must be subject to empirical scrutiny regarding its scope, accessibility, activities, processes and outcomes, moving beyond generalisations to more critical assessment and engagement with this area of work (Oakley et al, 1998; Little, 1999). However, the aims, intended recipients, key decisions and methods of family support are very broadly described and minimal data are collected on the activities undertaken, making it difficult to research and measure (McCroskey \& Meezan, 1998; Pinkerton et al, 2000). This may reinforce the marginalization of family support, because it is a somewhat elusive concept, both an approach to child welfare practice and a set of services with a preventative aim.

While there is justification for regarding family support as integral to improving the safety and well-being of vulnerable children, the promotion of a family support approach should not be uncritical. Its contribution to effectiveness requires more attention at both theoretical and empirical levels. This article examines the specifics of family support service provision in one jurisdiction and explores issues arising from collecting programwide performance data. It presents results from a system-wide survey of family support services in a single jurisdiction using a performance measurement framework.

\section{The study}

This study examines family support as part of a 'systemic reform effort that transcends individual programs and services' (Pecora et al, 1995, p.17). It concentrates on services beyond those (more) universally available in spheres such as health, education, child care 
or income support, and excludes those with aims not directly related to the care of children, such as domestic violence services or drug and alcohol counselling, notwithstanding that these services may also contribute to children's well being. That is, they have a policy aim of protecting the safety of children and promoting their wellbeing. This might be considered a narrow definition of family support in as much as it is concerned with those services that have purposes directly linked to child welfare. However, the development of targeted family support services is an acknowledgement that there are families for whom universal preventative services are not sufficient, and some children are missing out on help because their parents face personal or social barriers to accessing needed services. In Australia, family support services included in this definition provide information and referral, counselling and mediation, parent skills training and other educational skills development, advocacy, home visiting and other inhome support (Australian Institute of Health and Welfare, 2001). Most are provided by non-government or voluntary agencies. They are typically located in neighbourhood houses or community centres, community health centres or within a multipurpose welfare agency.

The study describes family support across the whole jurisdiction: the number of children, young people and families who received assistance from family support services, their needs, and the services they received. The data were not collected for the evaluative purpose of measuring performance, but to begin to understand family support at a system-wide level, in quantitative terms. The study is essentially descriptive, using the logic of performance measurement as a way to 'unpack' family support. The survey 
sought to cover the whole field in order to capture the diversity of models and agency types within the family support sector, all operating with different local demographics.

\section{Methods}

The concept of family support is operationalized in standard performance measurement terms of inputs, outputs, processes and outcomes. These dimensions are defined in Table 1. The survey was undertaken via a mail-administered census of client-related work undertaken in a 'typical' week in October 2002. Two types of data were obtained. Firstly, general agency information about funding, staffing, programs, and agency objectives was recorded by the agency manager. Secondly, data relating to any client receiving services from a family support worker during the census week were sought. For each occasion of service, that is every time a client was seen or spoken to by a family support worker in order to provide assistance or support, the answers to fifteen questions relating to the output, process and outcome indicators set out in Table 1 were recorded by the frontline worker. It was not expected that the worker would ask the client the questions, it was anticipated that most of the information would arise during normal contact with the client, as turned out to be the case.

INSERT TABLE 1 ABOUT HERE

\section{Results}

\section{Respondents}

Thirty-nine agencies from the total of 120 participated in the survey, providing a 32.5\% response rate. The characteristics of the respondent agencies were similar to the characteristics of the total population in terms of their geographical distribution 
throughout the state, their funding profile, and whether government, community or church-based. Results can be extrapolated, with care, to the total population.

\section{Inputs}

Funding and staffing: In 2001-2002, funds allocated to all 120 agencies totaled $\$ 10.4$ million, compared to expenditure of $\$ 129.7$ million for child protection and out-of-home care (Steering Committee for the Review of Commonwealth/State Service Provision, 2003). The 39 respondent agencies received funds of $\$ 4.7$ million. Most agencies (74.4\% of respondents) received less than $\$ 100,000$ per annum—-that is, funding for one full-time worker at most. There were 42 full-time and 65 part-time family support workers employed in 38 agencies (one unknown). Most agencies (32 of 39) had at least one worker with tertiary qualifications in human services and social work degrees were the most common qualification. The family support program had an experienced workforce. For all workers for whom years of experience in human services was known ( $\mathrm{n}=92), 43$ had over ten years experience, 22 had between five and ten years experience, 21 had between two and five years experience, and six workers had less than two years experience. About one-third of agencies $(n=14)$ used volunteers to undertake family support work. While five agencies had just one or two volunteers, nine agencies used volunteers extensively—a total of 161 between them (average 17.9). The agencies were all direct service providers. There was one government-run agency, about one-third were Church-based agencies and the remaining two-thirds were local community-based nongovernment agencies. 
Client profile: During the census week, a service was provided to 1083 distinct clients. On most occasions, the family member presenting for assistance or support was the mother (63.0\%), followed by the child or young person (17.0\%) and the father (11.3\%). Other persons presented on $8.8 \%$ of occasions. Services were provided fairly equally to two-parent families (40.0\%) and single-parent families (43.0\%). Families in which the children were in care also received a small proportion of services (3.2\%). Over half of all clients relied on government pensions or benefits as their main form of income (58.3\%). Almost one-third (28.9\%) had permanent full-time employment, $11.5 \%$ had part-time, temporary or casual employment, and ten clients (1.2\%) had no income. Services related to children of all ages. In $4.9 \%$ of cases the mother was pregnant and the service related to the expected child. In $17.2 \%$ of cases the service did not involve any concerns about a child or young person.

Most clients were Australian-born (91.1\%). For 92.6\% of clients English was the only language spoken at home, with $7.4 \%$ of clients speaking another language at home. This is slightly less that the total state population of which $11.5 \%$ spoke a language other than English at home (Australian Bureau of Statistics 2002). For the clients who spoke another language, the vast majority (88.5\%) spoke English well or very well. Only eight clients did not speak English well. This tends to indicate people with limited English language skills had poor access to these family support services. Access for Aboriginal and Torres Strait Islander clients was better, as might be expected as two of the respondent agencies were established specifically for those client groups. Aboriginal and/or Torres Strait 
Islander clients comprised $10.4 \%$ of total clients, and $6.4 \%$ of clients in agencies not specifically targeted at Indigenous clients. Aboriginal and Torres Strait Islander people comprised 3.1\% of the state population at the 2001 census (Australian Bureau of Statistics, 2002).

\section{Outputs and processes}

Occasions of service: During the census week, a service was provided to clients on 1198 occasions, involving 1083 distinct clients (115 clients were seen on more than one occasion during the week). On average, each agency saw 27.8 clients during the week. The number of clients seen during the week ranged from five clients in one small agency to 254 clients in the largest agency. Therefore each full time equivalent worker provided on average 16.1 occasions of service during the week. These occasions of service involved direct contact with clients, it did not involve other agency work or follow-up or preparation work on behalf of clients.

Client needs: Workers were asked to determine the nature of client issues or problems and select the main reason that services to clients were provided (that is, client needs cause a demand for services). A selection was made from pre-set categories of client issues or problems. The categories were adapted from England's annual census of services for children in need (Department of Health, n.d.). Two categories could be prioritized. The most common issues or problems identified were family or parental stress (40.2\%); ongoing family problems (15.1\%); adolescent behavior (8.8\%); low income (4.3\%); abuse or neglect (5.8\%); child illness or disability (4.3\%); parental illness 
or disability (4.9\%); other issues or problems (15.9\%). When the first and second issue categories were combined, for about one-third of service transactions, 'temporary' family problems were identified (family or parental stress) and for another one-third more serious and ongoing problems concerning care of children were evident (combining ongoing family problems, adolescent behaviour and abuse or neglect). Almost one-fifth of clients (18.1\%) had been contacted by, or notified to, the state child welfare department regarding child protection concerns during the past twelve months. This indicates a level of seriousness of concerns about the care of children.

Support and assistance provided: Workers were asked to nominate the types of services provided in response to these identified needs. Two kinds of support could be identified. The most commonly provided support or assistance was individual or family counseling, interpersonal support or mediation. The second most common response was information, advice and referral. Together, these two accounted for $67.4 \%$ of first responses. Of the first types of support, only $8.3 \%$ were concrete services addressing a specific practical need in the family (combining advocacy, respite care and other support). Another $41.3 \%$ were educational or enabling services (combining information/advice/referral, parenting and household skills development, needs assessment and case management). Clinical services such as counseling and development of social supports comprised $50.5 \%$ of support types (categories adapted from Cash \& Berry, 2002).

On a continuum of child welfare work, most agencies located their family support work at the secondary prevention level, as follows: 


\begin{tabular}{|c|c|c|c|c|c|}
\hline $\begin{array}{l}4 \text { agencies } \\
\downarrow\end{array}$ & $\begin{array}{l}11 \text { agencies } \\
\downarrow\end{array}$ & $\begin{array}{l}9 \text { agencies } \\
\downarrow\end{array}$ & \multicolumn{2}{|c|}{$\begin{array}{l}4 \text { agencies } \\
\downarrow\end{array}$} & $\begin{array}{l}1 \text { agency } \\
\downarrow\end{array}$ \\
\hline $\begin{array}{l}\text { Whole of cc } \\
\text { Universal s } \\
\text { Primary pr }\end{array}$ & ty focus & $\begin{array}{l}\text { Targeted to at-ri } \\
\text { young people or fc } \\
\text { Secondary preven }\end{array}$ & $\begin{array}{l}\text { dren, } \\
\text { el }\end{array}$ & $\begin{array}{l}\text { Fami } \\
\text { diffic } \\
\text { Tertic }\end{array}$ & $\begin{array}{l}\text { th serious } \\
\text { aring for children } \\
\text { el }\end{array}$ \\
\hline
\end{tabular}

6 agencies stated they worked across the continuum

4 agencies - missing data

In most cases, a service was being provided as part of ongoing work with the client ( $57.8 \%$ of cases). A further $20.5 \%$ of cases were classified as intake, the first contact with a client in which need and eligibility was being assessed. In $21.6 \%$ of cases initial work was occurring whereby a service was being provided to the client not necessarily on an ongoing basis. Smaller agencies were more likely to provide ongoing services (for these, $73.9 \%$ were ongoing; $14.0 \%$ were initial work; and $12.1 \%$ were intake).

While most occasions of service were ongoing work in which it was expected the client would be seen again, $39.0 \%$ of service transactions took less than 30 minutes to complete. These data are reasonably congruent with earlier data regarding the type of support or assistance provided and tend to indicate that about $40 \%$ of agency work with clients involves short-duration, low-intensity transactions (mainly information, advice and referral) and another 50\% involves slightly longer duration transactions (mainly counseling and interpersonal support). There was no indication that more serious problems lead to more time being spent with clients. Regardless of the presenting issue or problem, between $30 \%$ and $40 \%$ of clients received less than thirty minutes service. Those for whom low income or 'other issues' were the main presenting problem were the 
most likely to receive less than 30 minutes and clients for whom parental illness or disability was the main issue were the least likely.

Referral source: The process by which clients 'find' a welfare agency can be instructive in indicating something about access to services, particularly whether clients actively sought help themselves and had the personal resources and confidence to ask for help, or whether family problems or concerns were identified by others who guided the client towards the agency. Access to services, particularly for those clients who are most in need of assistance, has become an increasing focus of discussion for family support services (Tomison, 2002). A high level of self referrals may indicate that an agency is not actively targeting specific client groups but providing services on a 'first come, first served' basis. This may mean those clients who are the most marginalized may not access services. Here, one-fifth of clients were self-referred (21.2\%), the state child welfare department referred $10.1 \%$ of clients, other human services agencies referred $14.8 \%$ and health services referred $10.1 \%$ of clients. Remaining clients were referred by family members or friends, schools or day care, other or unknown sources.

Methods of delivering services: In the majority of cases (55.8\%), services were provided in person. In $44.2 \%$ of cases, services were provided by telephone. This is skewed because one of the largest agencies that participated in the survey was a telephone counseling service for parents, which provided its services exclusively by phone. If this agency is excluded from the analysis, only $29.2 \%$ of services were provided by phone and $70.8 \%$ were provided in person. Note, the inclusion of this agency did not affect the 
types of services provided. Counseling and interpersonal support, followed by information, advice and referral remained the most common means of responding to client needs. Nor did its inclusion affect the length of time taken for each occasion of service.

On the occasions when services were provided in person, they were usually provided at the agency’s premises (49.5\%). Services were provided in the client’s home on $33.0 \%$ of occasions, and at other venues on $17.5 \%$ of occasions. In most cases, the response to clients involved individual work (65.3\% of services) but there was also some family work (19.9\%) and group work (11.5\%).

\section{Outcomes}

Measuring outcomes requires clarity in recording of outcomes intended and achieved, because outcomes are the impact, benefit, consequences or results of the service for the children, young people and families who are clients. Outcome measures answer the question: 'have services been effective in meeting client needs?' There are many approaches to family support, depending on the theoretical approach, program model, choice of methods, and so on, used by the worker and agency. Some approaches are more goal directed than others, but whatever approach is used, the worker generally gathers information to gauge what the client's needs are (makes an assessment) and then discusses with the client what those needs are, and how the worker can help (develops case goals). This is important for outcome measurement, because measuring whether client needs are met requires some statement or understanding about what change the 
intervention was expected to achieve. This is described as a 'goal attainment' approach to outcome measurement (Rapp \& Poertner, 1987). It is more amenable to measuring shortterm or intermediate outcomes than long-term outcomes. For the survey, workers were asked to indicate up to two case goals for ongoing clients who they expected to see again. For the cases that were not ongoing and no further service was being provided to the client, workers were asked to indicate up to two reasons for case closure.

Case goals: Two case goals could be stated from a pre-set list. For the 927 ongoing cases reported on in this survey, the current case goals for clients mainly related to improving family relationships (34.4\%), improved parenting skills, knowledge or attitudes (33.5\%) and improved parental self esteem (33.4\%). Over one in ten cases had either no goal (9.3\%) or an unknown goal (4.4\%).

Reasons for case closure: For the cases that were not ongoing and no further service was being provided to the client, workers were asked to indicate up to two reasons for case closure. The generic response 'client's needs were met fully or partially' was available. This was followed by more specific options derived from the goal statements indicating a positive change in the situation for the client (such as 'care of children improved', 'self esteem improved', or 'parent linked to social support'). Overwhelmingly the generic response was chosen. For the 193 cases in which a reason for case closure was supplied, 56.0\% were closed because the worker believed the client's needs were met, either partially or fully. There were very few cases $(n=18)$ in which specific improvements in the client's situation, linked to case goals, could be identified. Most of the remaining case 
closures were because the client withdrew, the client was ineligible for services, or the client was referred to another service. These responses accounted for $41.5 \%$ of all case closures.

\section{Discussion}

While limited data on outcomes were obtained from this survey, the descriptive output and process data were useful, particularly in highlighting patterns of service delivery. Data on the types of support and assistance provided and the modes of service delivery, when linked to the client profile data, raise important policy questions about the appropriateness of services in meeting the needs of clients. The survey shows that family support services comprise a reasonably narrow range of supports and assistance to families with 'temporary' problems mainly through short duration, low intensity transactions. Many families received only information, advice and referral. Services were mainly in-agency counseling, interpersonal support or mediation. A large part of family support resources were invested in telephone counseling. Almost $40 \%$ of all occasions of service (whether face-to-face or by telephone) took less than thirty minutes to complete. While this work is likely to be accompanied by collateral work undertaken on behalf of the client, which was not recorded in this survey, it does seem that not much time was actually spent engaging with clients. These issues raise concerns about the provision of family support services in this jurisdiction, although not necessarily about the concept of family support. Here, family support is not well-positioned as a vehicle for substantial change in child welfare in this jurisdiction: small in size, not well-funded, and providing a fairly minimal level of servicing. 
While one-off or time-limited interventions may be useful for some families, low intensity involvement of services is likely to be of limited use for families with chronic problems. A review of the knowledge base on neglect (Tanner \& Turney, 2003) found that a blend of concrete and therapeutic services was required, possibly for a lengthy period of time. Tailored, coordinated responses based on a comprehensive assessment were more likely to produce change than a 'scattergun' approach. Yet longer-term intervention is helpful only if it is purposeful and focused, with clear assessment and objectives for change, and ways of evaluating whether change has occurred. The inability or unwillingness of workers to indicate specific client needs that were met following intervention, plus the fact that many cases had no goal or an unknown goal, tends to indicate that service delivery does not meet these criteria. Lack of individualized assessment and intervention can mean that agencies define in advance for the client the problems that will be dealt with, thereby limiting choice and self-determination. This paucity of attention to assessment and case goals is consistent with research which found that the more formal the child welfare work, the better the assessment and planning, and concluded that thinking about outcomes and objectives in family support work was only in its infancy (Department of Health Social Services Inspectorate, 1999; 2001). An emphasis on processes such as 'nurturing', 'educating', and 'connecting to community' in family support may be perceived as more important than goal-setting (Healy \& Meagher 2001). Also, the short duration of service delivery in combination with the high proportion of information and referral is concerning because, in family support work, the role and function of the caseworker are crucial. Relationship building, assessment and 
engagement are vital (English et al, 2000) and do not obviate the need for a structured helping alliance with the family (Tanner \& Turney, 2003).

It might be argued that services should be offered to families whenever help is requested, and preferably before the level of need reaches a certain level of seriousness. But the idea of thresholds, that some families are 'at risk' and need 'extra' help, is inherent to family support. It follows then that those with low level needs should not be helped at the expense of those with higher level needs, especially if supports are minimal and there is little evidence they will substantially alter child and family trajectories (Axford et al, 2002). There is no intrinsic reason that those with more entrenched needs should be pushed into statutory services if the safety and well-being of the child can be secured using voluntary or community-based services. However, this may be the effect of untargeted 'first-come, first-served' practices in family support services. It should be noted that this is a limitation of the performance measurement framework, as it explores only existing service provision, not unmet needs, thus not addressing questions about who is missing out on services.

Aside from the substantive data about the nature of family support, the study was useful in demonstrating the use of a performance measurement framework in family support. Collecting performance data on a program-wide scale, even basic data about inputs, outputs, processes and intermediate outcomes, makes a useful contribution to empirical knowledge in this area. The performance measurement framework provides the capacity to understand the contribution of family support that takes analysis beyond the limitations 
of practitioner/agency self-reports, or meta-evaluations. Provided data are carefully interpreted, they can be useful to ask policy-relevant questions and improve practice. There are other examples of the usefulness of these kinds of administrative data to understand child welfare policy and practice. For example, research into the processes whereby many children and families were filtered out of the child protection system without receiving any type of help (Gibbons et al, 1995) involved analysis of output data including the numbers of referrals, children on child protection registers, investigations and children in care. Also, the extent to which children from minority racial and ethnic groups are over-represented or under-represented at various stages of the child welfare process can be used to understand the precise dimensions of, and reasons for, race disproportionality (for example, Needell et al, 2003). Such quantitative data can powerfully illuminate aspects of professional practice or management. Of course, this quantitative lens on family support is not the total picture. It does not probe in detail the processes by which family support services might engender positive change in families, as might be revealed in an in-depth qualitative study. Data collection tools that are based on information obtained during the normal course of work with a client (a characteristic of administrative data, in contrast to data collections designed for a specific research purpose) necessarily restrict the scope of data that can be obtained, or else a high proportion of 'unknown' responses are made. The need to select one response from multiple response categories was a limitation of this survey. Nevertheless, such data are part of a broader picture that may contribute to our understanding of family support, particularly since there are so few quantitative studies in this area. The development of data requirements for children's social services in England and Wales for the Integrated 
Children's System is likely to yield an administrative data set useful for understanding and describing service provision to children in families on a broader scale than is currently available.

There are objections to performance measurement nested within the broader critique of the 'new public management'. This points to, among other things, the limitations of a rational/technical approach which assumes government policies and programs can be objectively defined, measured and managed and the inappropriateness of applying private sector business principles to the public sector (Sanderson, 1998). Concerns about performance measurement include, for example, that objectives may be narrowly defined, that intangible client benefits may not be counted, that the importance of the social work 'process' may become subservient to 'outcomes', that practice may become bureaucratised and defensive, and above all, that the pursuit of efficiency may divert attention from resource deficits and lead to a decline in the effectiveness, quality or availability of services (Martin \& Kettner, 1997; Munro, in press). However, rather than using performance indicators to make definitive judgments about performance, performance measurement can facilitate an open and reflective approach, bringing more clarity to how problems are understood and therefore where to look for solutions. There are multiple stakeholders involved in child welfare, all of whom may interpret performance data in different ways. Indicators of 'good practice' are not value-free, they represent viewpoints and values about child welfare. It is possible to conceptualize performance measurement not solely as a 'hard' tool that measures quantitatively, but also as a 'soft' tool, communicating ideas as well as 'facts'. That is, performance 
measurement has a normative role: communicating policy intent, shaping the way we think and talk about child welfare, defining notions of outcomes, effectiveness and quality. This makes it vital that performance measurement is harnessed in the interests of good child welfare practice that attends to both the quality of service delivery and positive outcomes for children and families.

Measuring the effectiveness of child welfare services depends upon assumptions about the primary goals of child welfare intervention in any policy regime. If child welfare services are intended to 'rescue children from bad parents' then the performance indicators selected to monitor success are likely to be different to those selected if the primary goal is to 'help disadvantaged parents care for their children'. There is an interactive relationship between performance measurement and policy, which implies that family support can be brought more into the mainstream of what is considered child welfare, rather than marginalized as an optional extra, if it is included in the child welfare performance measurement effort. Thus performance measurement, an important policy tool in the contemporary public sector context, can be used to strengthen the position of family support.

\section{Conclusion}

The question of outcomes that is raised by performance measurement, though difficult, is important for child welfare services to grapple with. Despite its claims to be voluntary, flexible and preventative in assisting families, it cannot be assumed that family support services will achieve positive changes for families: they may do nothing, or they may 
make the situation worse. It is important to move family support beyond policy rhetoric towards being a more substantial and integrated component of the child welfare system. This requires critical engagement with its scope, processes and impact. Results from this survey of family support services in one jurisdiction shows the limitations of current service delivery but demonstrates that a performance measurement framework might make a useful contribution towards understanding, monitoring and improving performance in this vital area of child welfare practice.

\section{References}

Aldgate, J. \& Hill, M. (1995) Child welfare in the United Kingdom. Children and Youth Services Review, 17(5/6), 575-597.

Aldgate, J., Tunstill, J. \& McBeath, G. (1992) National monitoring of the Children Act: Part III section 17 - the first year. Oxford University/NCVCCO, London.

Audit Commission (1994). Seen But Not Heard. HMSO, London.

Australian Bureau of Statistics (2002) 2001 Census of Population and Housing: Selected Social and Housing Characteristics for Statistical Local Areas, Queensland (cat. 2015.3). Australian Bureau of Statistics, Canberra.

Australian Institute of Health and Welfare (2001) Family support services in Australia 2000, AIHW, Canberra.

Axford, N., Little, M. \& Morpeth, L. (2002) Children Supported and Unsupported in the Community: a report on findings to date. Unpublished manuscript, Dartington Social Research Unit. 
Carter, N., Klein, R. \& Day, P. (1992) How Organisations Measure Success: The Use of Performance Indicators in Government. Routledge, London.

Cash, S. \& Berry, M. (2002) Family characteristics and child welfare service: does the assessment drive service provision? Families in Society, 83(5/6), 499-507.

Daro, D. (2003) Before substantiation: the role for child welfare agencies in preventing maltreatment. Paper presented at Child Welfare Services Research and its Policy Implications Conference sponsored by the Joint Center for Poverty Research held 20-21 March 2003, Washington DC.

Department of Health (n.d.) Chapter 4: Definitions of need codes. In Children in Need 2001: Guidance. Version 2.0. www.doh.gov.uk/cin/guidance4.pdf, accessed 26 April 2002.

Department of Health Social Services Inspectorate (1999) Inspection of the Delivery of Family Support Services. HMSO, London.

Department of Health Social Services Inspectorate (2001) Developing Quality to Protect Children: SSI Inspection of Children's Services. Department of Health, London.

English, D. J., Wingard, T., Marshall, D., Orme, M. \& Orme, A. (2000) Alternative responses to child protective services: emerging issues and concerns. Child Abuse and Neglect, 24(3), 375-388.

Faver, C. A., Crawford, S. L. \& Combs-Orme, T. (1999) Services for child maltreatment: Challenges for research and practice. Children and Youth Services Review, 21(2), 89-109. 
Frost, N. (1997) Delivering family support: issues and themes in service development. In: Child Protection and Family Support: Tensions, contradictions and possibilities. (Ed. N. Parton), pp. 193-211, Routledge, London.

Gibbons, J., Conroy, S. \& Bell, C. (1995) Operating the child protection system. HMSO, London.

Healy, K \& Meagher, G. (2001) Practitioner perspectives on performance assessment in family support services. Children Australia, 26, 4, 22-28.

Little, M. (1995) Child protection or family support? Finding a balance. Family Matters, 40, 18-21.

Little, M. (1999) Prevention and early intervention with children in need: Definitions, principles and examples of good practice. Children and Society, 13, 304-316.

Maluccio, A., Pine, B. \& Warsh, R. (1994) Protecting children by preserving their families. Children and Youth Services Review, 16, 295-207.

Martin, L. L. \& Kettner, P. M. (1997) Performance measurement: the new accountability. Administration in Social Work, 21(1), 17-29.

McCroskey, J. \& Meezan, W. (1998) Family-centered services: approaches and effectiveness. The Future of Children, 8(1), 54-71.

McGowan, B. G. \& Walsh, E. M. (2000) Policy challenges for child welfare in the new century. Child Welfare, 79(1), 11-27.

Munro, E. (in press) The impact of audit on social work practice. British Journal of Social Work.

Needell, B., Brookhart, M. A. \& Lee, S. (2003) Black children and foster care placement in California. Children and Youth Services Review, 25(5-6), 393-408. 
Oakley, A., Rajan, L. \& Turner, H. (1998) Evaluating parent support initiatives: lessons from two case studies. Health and Social Care in the Community, 6(5), 318-330.

Parton, N., Thorpe, D. \& Wattam, C. (1997) Child Protection: Risk and the Moral Order. Macmillan, Basingstoke.

Pecora, P. J., Fraser, M. W., Nelson, K. E., McCroskey, J. \& Meezan, W. (1995) Evaluating Family-Based Services. Aldine de Gruyter, New York.

Pinkerton, J., Higgins, K. \& Devine, P. (2000) Family Support - Linking Project Evaluation to Policy Analysis. Ashgate, Aldershot.

Rapp, C. \& Poertner, J. (1987) Moving clients centre stage through the use of client outcomes. Administration in Social Work, 11(3/4), 23-37.

Sanderson, I. (1998) Beyond performance measurement? Assessing 'value' in local government. Local Government Studies, 24(4), 1-25.

Statham, J. \& Holtermann, S. (2004) Families on the brink: the effectiveness of family support services. Child and Family Social Work, 9, 153-166.

Steering Committee for the Review of Commonwealth/State Service Provision (2003) Report on Government Services 2003. Protection and Support Services Attachment 15A, table 15A.1. Productivity Commission, Canberra.

Tanner, K. \& Turney, D. (2003) What do we know about child neglect? A critical review of the literature and its application to social work practice. Child and Family Social Work, 8, 25-34.

Tomison, A. M. (1999) Ensuring the protection of children: the role of child protection services in the identification, assessment and treatment of maltreated children. 
Paper presented at Department of Community Services 'Entry parameters to child and family services' workshop held 22-23 March 1999, Sydney.

Tomison, A. M. (2002) Preventing child abuse: changes to family support in the 21st century. Child Abuse Prevention Issues, 17, 1-22.

Tunstill, J. (1995) The concept of children in need: The answer or the problem for family support? Children and Youth Services Review, 17(5/6), 651-664.

Waldfogel, J. (1998) The Future of Child Protection. Harvard University Press, Cambridge.

Whittaker, J. K. (1991) The leadership challenge in family-based services: policy, practice and research. Families in Society, 72(5), 294-300.

Wilding, J. \& Thoburn, J. (1997) Family support plans for neglected and emotionally maltreated children. Child Abuse Review, 6, 343-356. 
Table 1: Family support survey

\begin{tabular}{|c|c|c|c|c|}
\hline CONCEPT & \multicolumn{4}{|c|}{ FAMILY SUPPORT SERVICES } \\
\hline DIMENSIONS & INPUTS & OUTPUTS & PROCESSES & $\begin{array}{l}\text { OUTCOMES } \\
\text { FOR } \\
\text { CHILDREN } \\
\text { AND } \\
\text { FAMILIES }\end{array}$ \\
\hline $\begin{array}{l}\text { OPERATIONAL } \\
\text { DEFINITIONS } 1\end{array}$ & $\begin{array}{l}\text { Resources to } \\
\text { operate the } \\
\text { service }\end{array}$ & $\begin{array}{l}\text { Services or } \\
\text { activities } \\
\text { provided }\end{array}$ & $\begin{array}{l}\text { Methods of } \\
\text { delivering } \\
\text { services }\end{array}$ & $\begin{array}{l}\text { Intended benefit } \\
\text { or result for } \\
\text { clients }\end{array}$ \\
\hline INDICATORS & $\begin{array}{l}\text { Funding } \\
\text { Staffing } \\
\text { Client profile }\end{array}$ & $\begin{array}{l}\text { Occasions of } \\
\text { service } \\
\text { Type of need } \\
\text { Type of support } \\
\text { or assistance } \\
\text { Intake, initial or } \\
\text { ongoing cases }\end{array}$ & $\begin{array}{l}\text { Referral source } \\
\text { In home, in } \\
\text { agency or by } \\
\text { telephone } \\
\text { Individual, } \\
\text { family or group } \\
\text { work }\end{array}$ & $\begin{array}{l}\text { Case goals } \\
\text { Reasons for case } \\
\text { closure }\end{array}$ \\
\hline
\end{tabular}

Note 1: Definitions from Carter, Klein \& Day, 1992, p.35. 